\title{
Double Stage Pre-Filter Diesel Water SeParator
}

\author{
Fernando Jun Yoshino, Fábio Moreira, Felipe Ferrari and Tadeu Geraldo Domingues \\ MAHLE Metal Level S/A \\ E-mails: fernando.yoshino@br.mahle.com, fabio.mmoreira@br.mahle.br, \\ felipe.ferrari@br.mahle.com and tadeu.domingues@br.mahle.com
}

\begin{abstract}
Nowadays, water separation from diesel fuel is a critical requirement for modern diesel engines. The main reasons are: corrosion, wear on the fuel system, irregular combustion and acceleration of microbiological growth that clogs filters, pumps and pre-filters. Due to this, a pre-filter is placed at chassis side between fuel tank and pressure pumps in order to separate water from diesel.
\end{abstract}

However, this function is getting even more difficult because of higher biodiesel content. Higher biodiesel levels mean higher water absorption due to its higher hygroscopic characteristic. Additionally, it is more difficult to separate water from diesel due to biodiesel higher bond to water molecules. In this way, new pre-filters concepts are under development considering higher water separation efficiencies.

This paper presents a new product concept based on double-stage filtration technology. At this configuration, small water droplets are first coalesced and contaminants retained by a first stage. In a second stage, protected from contamination, final water separation happens. In order to illustrate technology potential, laboratory and field tests with prototypes are presented in order to confirm concept robustness at this new boundary condition.

\section{INTRODUCTION}

Diesel engines are improving in order to attend new government emission regulations and customers fuel consumption reduction requests. In this way, new diesel common-rail engines have been launched with higher injection pressures in order to attend these demands. At same time, these new technology engines require new boundary conditions to work in these straight limits. Main boundary condition is the fuel quality. Fuel quality is critical because new engines are more sensitive to contaminant presence, sulfur and water level contents. Depending on their presence level, fuel injection systems reduce their performance and durability.

Water content is one of these important fuel quality characteristics. When present in high levels, it causes fuel injection system corrosion and premature wearing. Beside this, water presence also contributes for microorganism growth at gas stations and truck tanks. This process creates a biological sludge that clogs fuel filters, fuel lines and fuel injection systems [1]. 
Due to this, government agencies are demanding water content level reduction at new diesel and biodiesel quality specifications [2]. However, diesel and biodiesel are hygroscopic fuels. It means that a good quality diesel released at production can increase its water content level during transportation and storage at gas station, changing to an out-of-specification diesel condition.

In order to avoid these problems, a pre-filter water separator is placed between fuel tank and fuel injection system as showed in figure 1. Filter function is to separate water from diesel during engine operation. Its performance is defined by fuel injection system supplier in order to assure fuel injection system performance and durability [3].

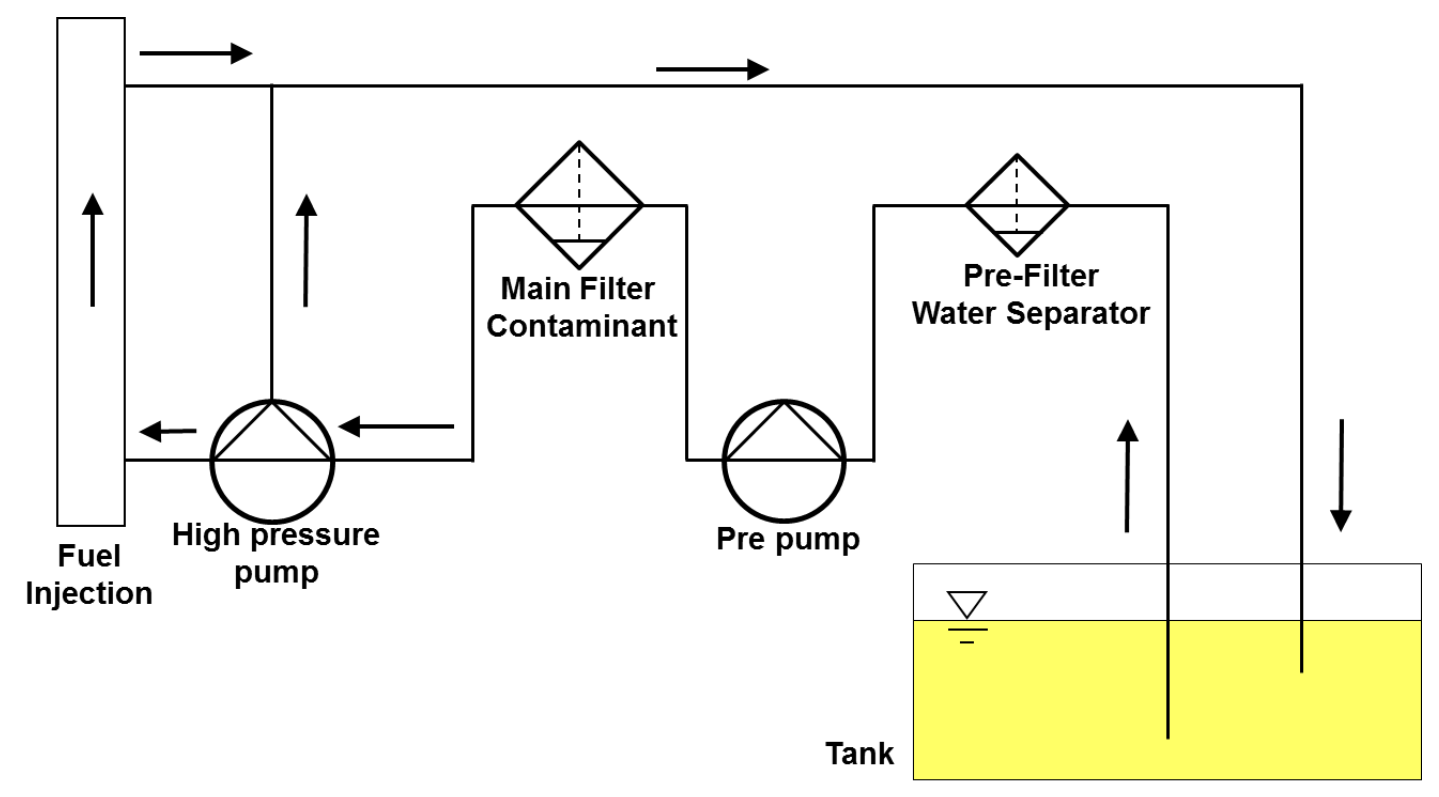

Figure 1: Typical fuel line circuit at medium and heavy duty trucks

\section{BIODIESEL INFLUENCE AT WATER SEPARATION FUNCTION}

However, water separation function is getting even more difficult. One of the reasons is the biodiesel presence. Biodiesel increases filtration effort to separate diesel and water. In addition, biodiesel is more hygroscopic than regular diesel, increasing water percentage levels during fuel storage.

As showed in the figure 2, there is a relation between biodiesel percentage increase and diesel/water chemical relation. As biodiesel percentage increases, lower interfacial tension and higher separability time are measured until $20 \%$ content is reached. After this point, both values tend to be stable at a reduced condition [4]. Low interfacial tension and high separability time are linked to diesel qualities where diesel and water molecules demand high effort to separate them. As showed in the figure 3, filtration technologies are sensitive to this fuel parameters variation and their water separation performance reduced. 

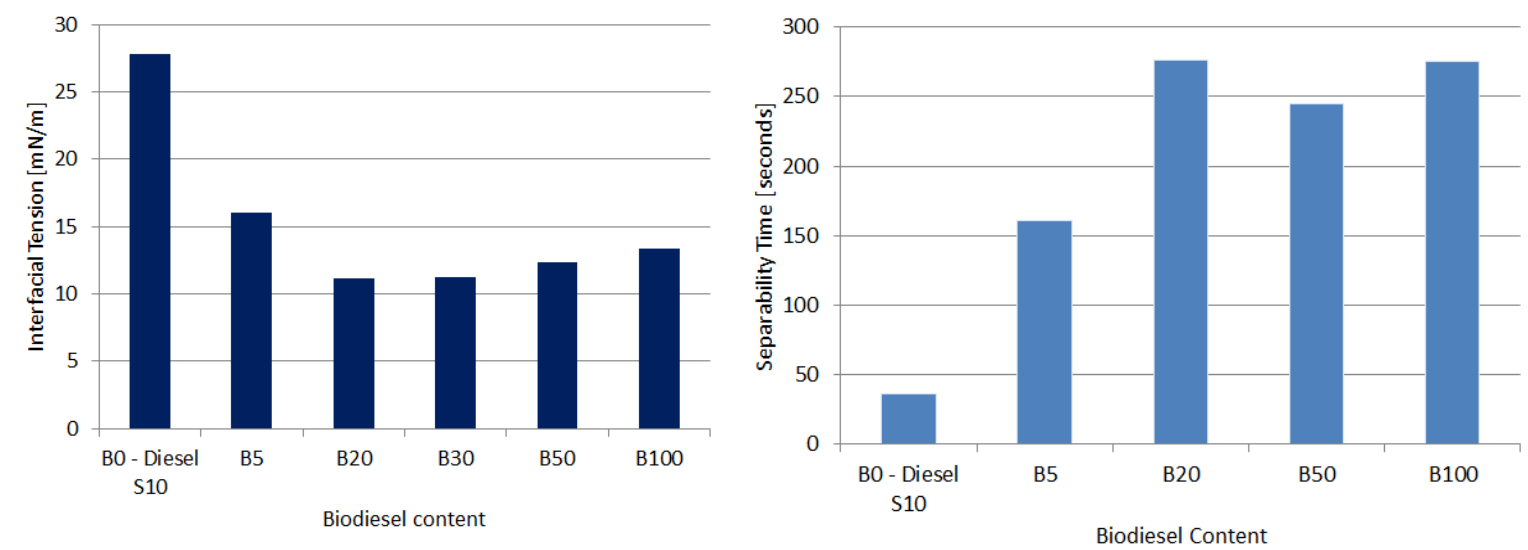

Figure 2: Interfacial tension and separability time against biodiesel percentage at $40^{\circ} \mathrm{C}$

\begin{tabular}{|c|c|c|c|c|}
\hline $\begin{array}{c}\text { Repetitions of } \\
\text { test with same } \\
\text { filter }\end{array}$ & $\begin{array}{c}\text { Diesel S500 B5 } \\
\text { IFT: } 13,1 \mathrm{mN} / \mathrm{m} \\
\text { Separability: } 360 \mathrm{sec} .\end{array}$ & $\begin{array}{c}\text { Diesel S500 B5 } \\
\text { IFT: } 12,7 \mathrm{mN} / \mathrm{m} \\
\text { Separability: } 10.800 \mathrm{sec} .\end{array}$ & $\begin{array}{c}\text { Diesel S10 B0 } \\
\text { IFT: } 22,86 \mathrm{mN} / \mathrm{m} \\
\text { Separability: } 13 \mathrm{sec},\end{array}$ & $\begin{array}{c}\text { Diesel S500 B5 } \\
\text { IFT 12,89 mN/m } \\
\text { Separability: } 150 \mathrm{sec} .\end{array}$ \\
\cline { 2 - 5 } & \multicolumn{2}{|c|}{ Filter Type A } & \multicolumn{2}{|c|}{ Filter Type B } \\
\hline 01 & $95 \%$ & $95 \%$ & $94 \%$ & $79 \%$ \\
\hline 02 & $95 \%$ & $94 \%$ & $98 \%$ & $85 \%$ \\
\hline 03 & $95 \%$ & $94 \%$ & $97 \%$ & $83 \%$ \\
\hline 04 & $95 \%$ & $96 \%$ & $96 \%$ & $83 \%$ \\
\hline 05 & $94 \%$ & $70 \%$ & $98 \%$ & $81 \%$ \\
\hline 06 & $96 \%$ & $0 \%$ & $96 \%$ & $85 \%$ \\
\hline 07 & $95 \%$ & $7 \%$ & $98 \%$ & $84 \%$ \\
\hline 08 & $96 \%$ & $8 \%$ & $96 \%$ & $8 \%$ \\
\hline 09 & $94 \%$ & $9 \%$ & & \\
\hline
\end{tabular}

Figure 3: Water separation efficiency affected by different Interfacial Tension (IFT) and Separability time with same filtration technology

Biodiesel is also more hygroscopic than normal diesel. As showed in the figure 4, when in contact to water during sixteen days, $100 \%$ biodiesel B100 water content increased from $500 \mathrm{ppm}$ to $1300 \mathrm{ppm}$ within two days. Additionally, comparing pure diesel B0 to 5\% biodiesel B5, 20\% biodiesel B20, 50\% biodiesel B50 and 100\% biodiesel B100, it is possible to identify a clear correlation between biodiesel percentage increase and hygroscopic function [5].

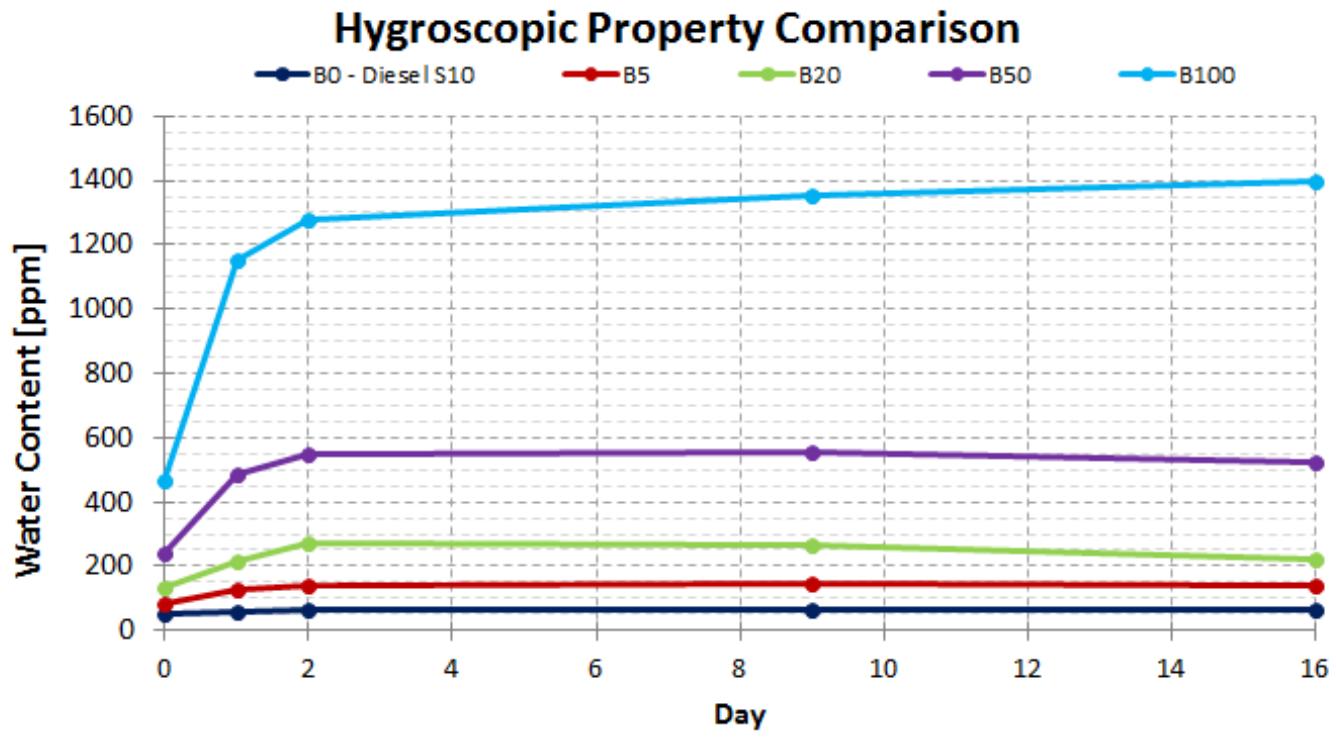


Figure 4: Biodiesel hygroscopic property comparison

In this way, a critical scenario is foreseen for new technology engines. Besides their more restricted requirements, water separation function is getting more difficult and more water is present at fuel as biodiesel percentage is increasing during last years. As an example, Brazil government revised previous 5\% biodiesel percentage to 6\% up July 2014 and $7 \%$ up November 2014 [6].

\section{CONTAMINANT INFLUENCE AT WATER SEPARATION FUNCTION}

Current pre-filter technologies are based on single stage water separation concept. In this case, water is separated from diesel through a media superficial separation effect. Water droplets have their size increased and, as soon as they achieve a minimum size, they move to filter water transparent bowl.

This technology presents high water separation efficiency levels when filter is brand new. However, when submitted to contamination, its water separation function is reduced. Main reason is related to this superficial water separation property. When contaminants are brought by the fuel to the media surface, it covers the single stage media surface and affects its water separation performance.

As showed in the figure 5, 13 pre-filters were collected from truck dealers. These parts were replaced during service interval according to truck manufacturer recommendations and using original equipment samples. Most of them have a differential pressure below the recommenced maximum 400 mbar @ 300 liters/hour flow rate requirement.

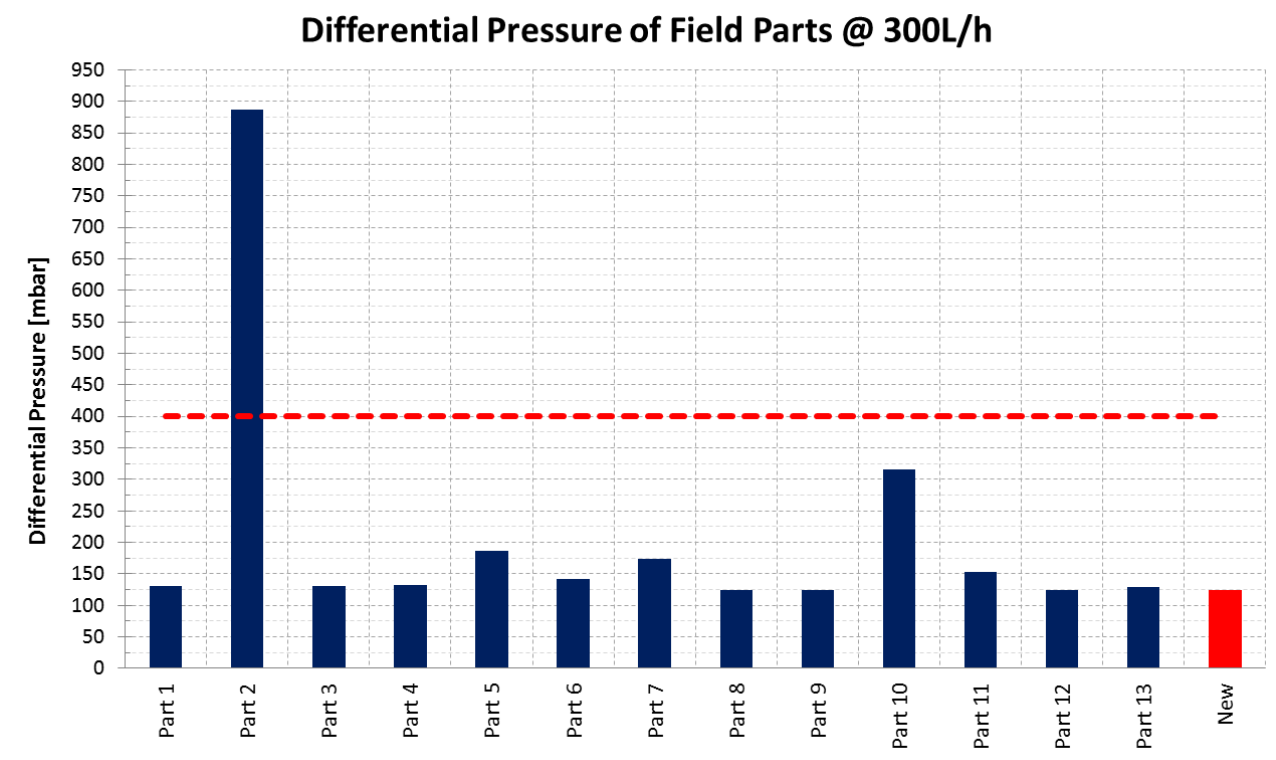

Figure 5: Differential pressure from field collected parts

However, when water separation efficiency was measured in these parts, all of them presented low water separation efficiency as showed in the figure 6. Even a low differential pressure sample with 125 mbar (quite similar to brand new filter) presented low water separation efficiency. 


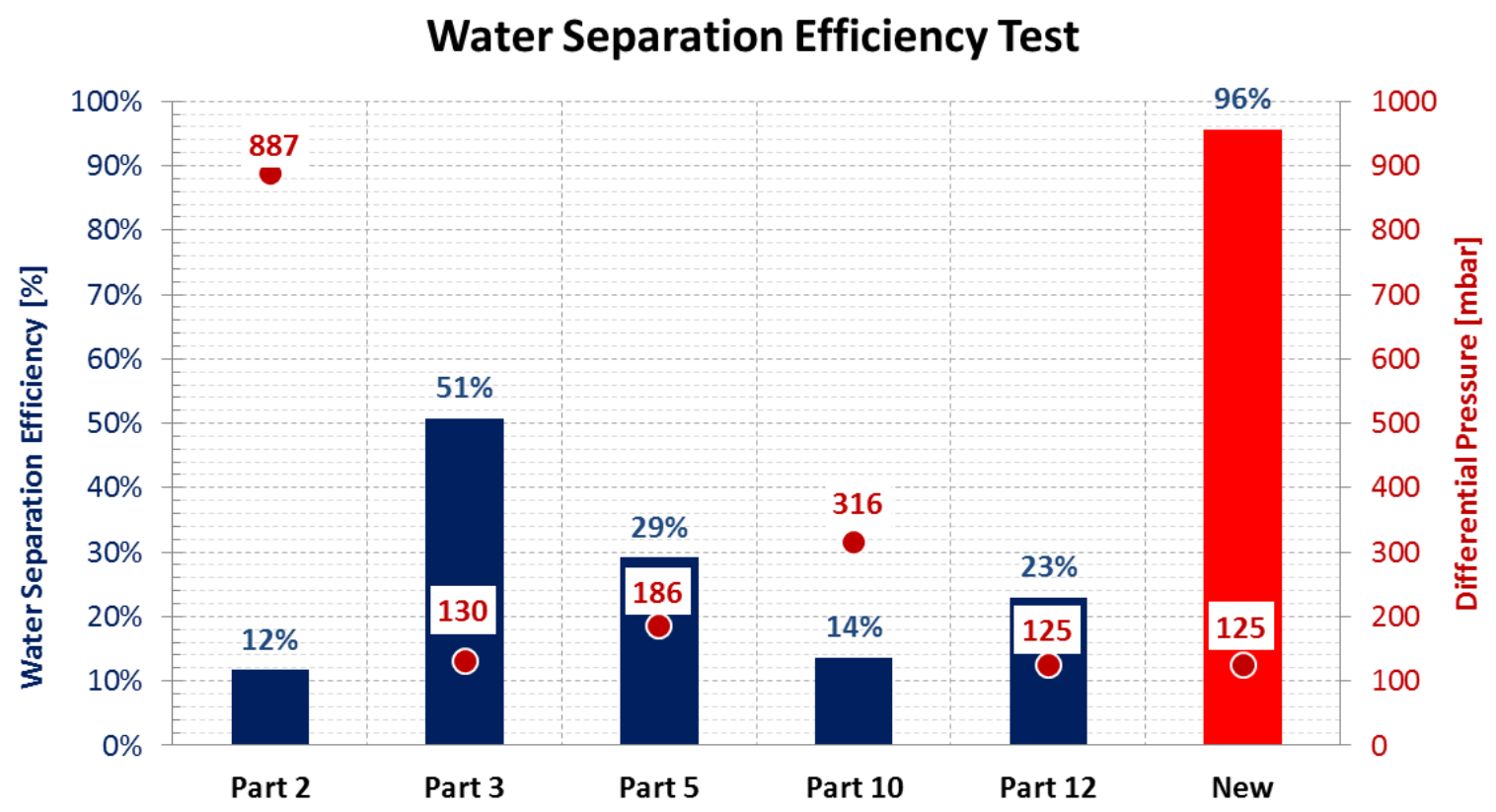

Figure 6: Water separation efficiency from field collected parts according to ISO TS 16332[7] specification and 300 liters/hour flow rate

As showed in figure 7, when filters were opened and filtration element checked, all samples presented high superficial contamination over the media filtration stage. It means that they were really exposed to field contamination and its water separation efficiency affected.
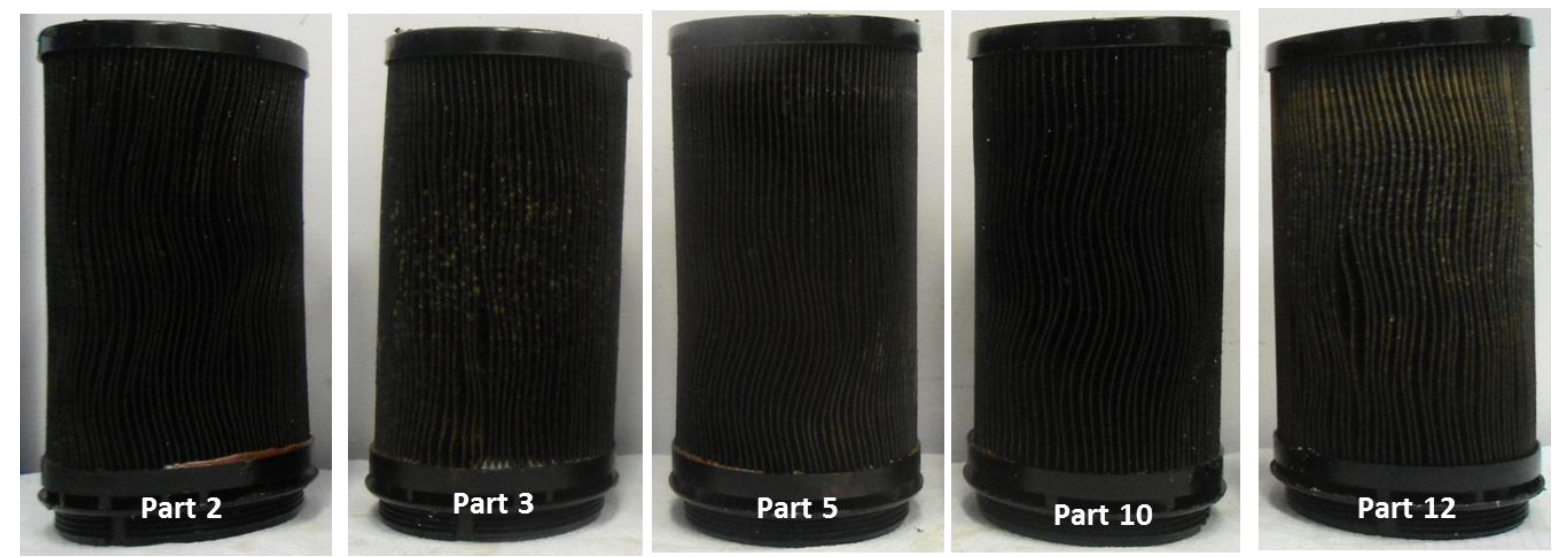

Figure 7: Field contaminated filter elements

In this way, product validation needs to consider not only brand new filter condition, but also contamination affected condition. In real life conditions, filters are exposed to several contamination levels and water separation function needs to be kept and checked. 


\section{NEW PRODUCT CONCEPT: DOUBLE STAGE PRE FILTER}

In order to assure water separation function in high levels considering biodiesel and contamination effects, new product concept named Double Stage Pre-Filter was developed as showed in the figure 8. Main idea is to separate water and diesel through two stages as showed in the figure 9. First stage is responsible for water coalescence and contaminant filtration. Second stage is responsible for final water separation.
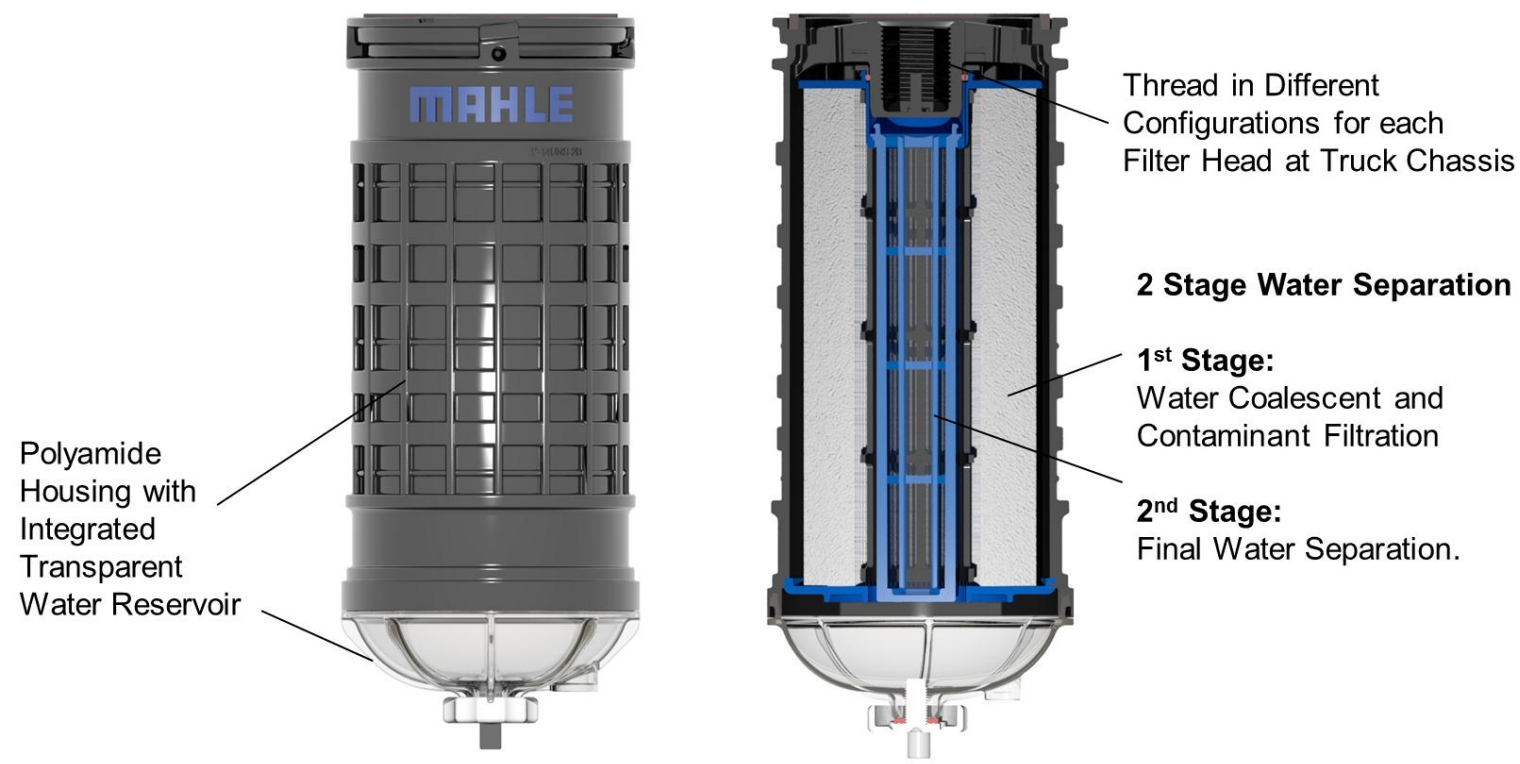

Figure 8: Double Stage Pre-Filter Water Separator

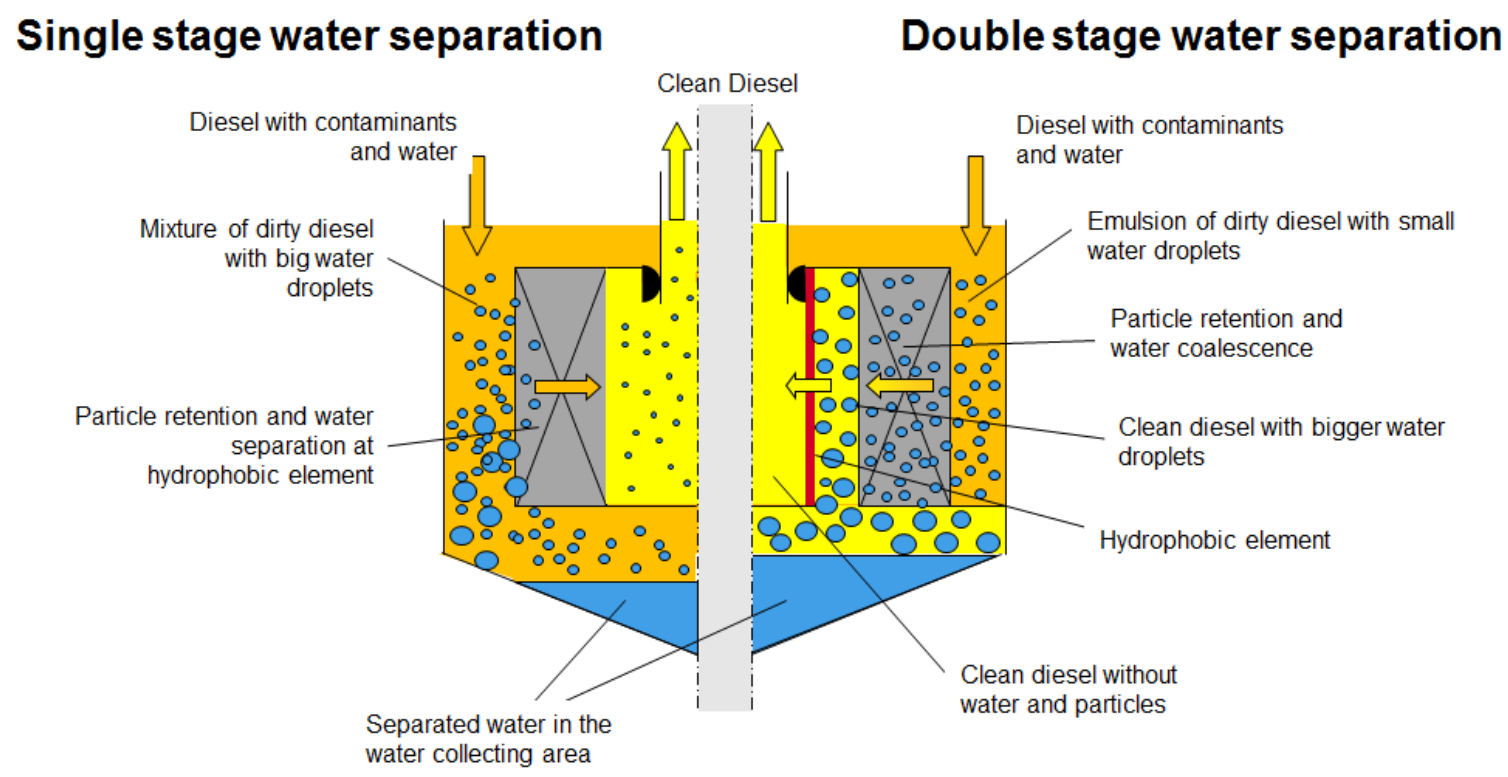

Figure 9: Double stage water separation concept in comparison to single stage water separation concept 
Considering higher biodiesel percentages, diesel and water separation effort is higher. In this way, the first stage is responsible to change the quite small water droplets in reasonable water droplet sizes. In this way, second stage final separator task is simplified and its efficiency kept on a high level over much longer intervals.

Higher water content levels found in biodiesel are also not a problem, as first stage media responsibility is not retain the water droplet. In this way, there is no water saturation within the media and function kept under severe conditions.

Contamination effect is also minimized as final water separation and filtration contamination functions are kept in different stages. First stage retains the diesel contamination and second stage is protected from dirt to work purely for a most effective water separation.

\section{DOUBLE STAGE TEST RESULTS}

In order to check new concept performance at severe conditions, prototypes were implemented and tested with laboratory and real life contamination as showed in the figures 10 and 11. Competitor's samples were tested in the same basis to evaluate performance in the same conditions.

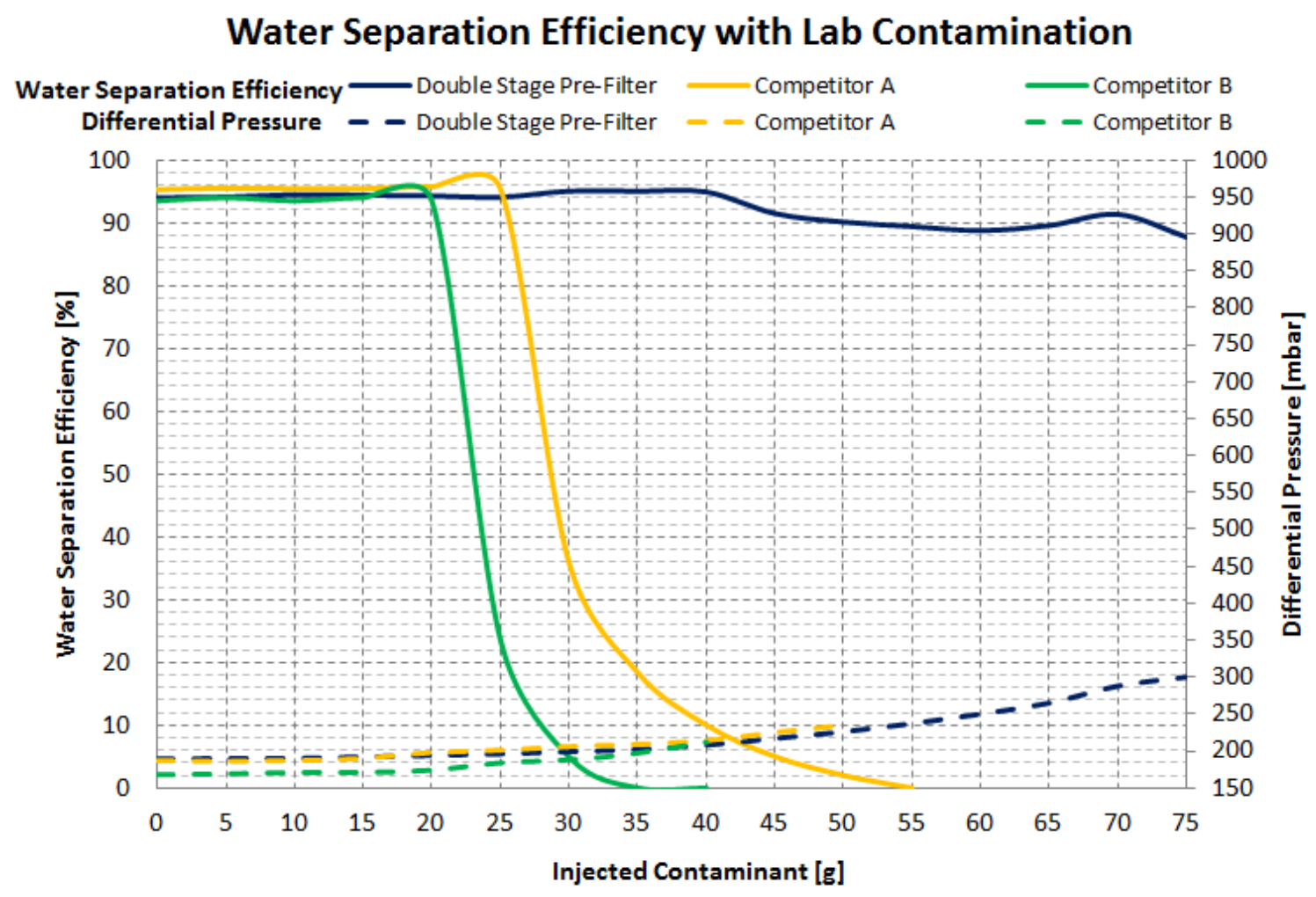

Figure 10: Double Stage and competitor's water separation efficiency according to ISO TS 16332[7] and differential pressure with ISO Fine contamination 


\section{Water Separation Efficiency with Field Contaminant}

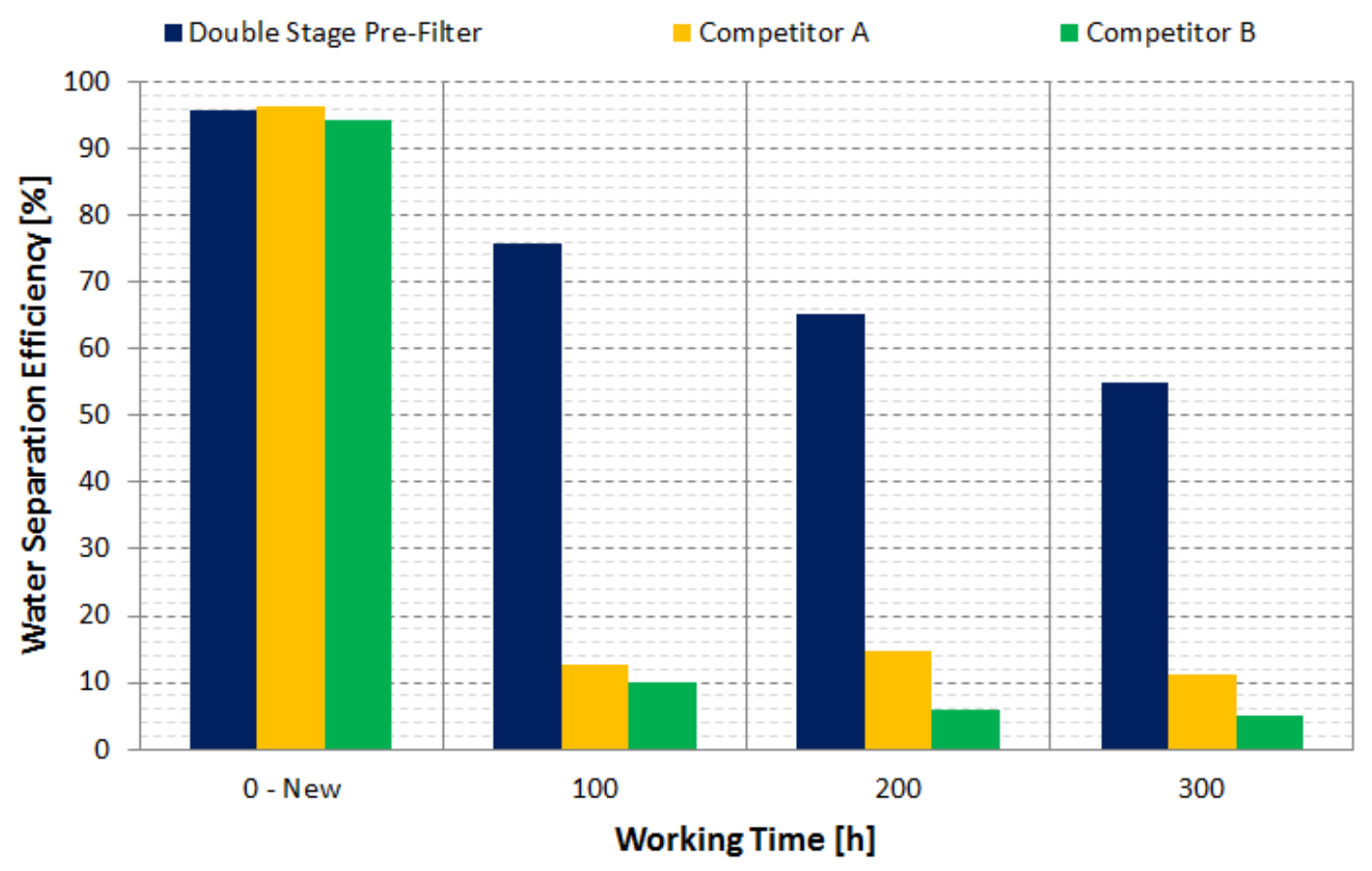

Figure 11: Double Stage and competitor's water separation efficiency according to ISO TS 16332[7]

\section{CONCLUSIONS}

New diesel engine technology requires special attention to diesel quality issues and real life conditions. In specific, the water separation efficiency is a critical driver for engine performance and durability. Based on presented paper, biodiesel percentage and contamination conditions are critical to define the correct boundary conditions for filter evaluation. Depending on biodiesel percentage and contamination levels, some filtration technologies fail in their function and do not keep the requested efficiency levels.

New concept based on double stage filtration was also presented in order to close current technology gaps. Double stage water separation presented good filtration performance in current B7 diesel condition and severe contamination levels. Using laboratory ISO Fine contamination, water separation was kept over 70 grams against 20 grams and 25 grams presented by competitors. Using real life contamination at a fuel circulation bench test, different working time conditions were evaluated. Considering 100 hours condition that simulates $30.000 \mathrm{Km}$ service interval, water separation efficiency was kept over $70 \%$ for double stage against competitors, single stage, results under $15 \%$.

In this way, Double Stage concept represents a robust solution to these market challenges and a trend to follow in the next pre-filter water separator generations. 


\section{REFERENCES}

[1] Fecombustíveis. [On-Line] www.fecombustíveis.org.br/relatorio-2011/biodiesel/aimdaem-busca-de-respostas.html.

[2] ANP. [On-Line] www.anp.org.br.

[3] 0449 D00 006, BOSCH: Diesel Systems Technical Customer Documents Common Rail Test Method Sheet. 14 ${ }^{\text {th }}$ April 2010.

[4] YOSHINO, Fernando Jun; FERRARI, Felipe; MARQUES, Gisela Ablas. Water Separation Challenge for Brazilian Diesel Engine. SAE 2013-01-1693. Detroit. 2013.

[5] CAVALCANTI E., PACHECO H.; Estudos de Degradação do Biodiesel e Misturas através de Ensaios de Envelhecimento Acelerado e de Corrosão do Aço através de Ensaios de Perda de Massa. Instituto Nacional de Tecnologia. Rio de Janeiro. October 2010.

[6] G1 Portal Notícias. [On-Line] http://g1.globo.com/economia/noticia/2014/09/governosanciona-elevacao-de-percentual-de-biodiesel-no-diesel-20140925074006058660.html

[7] ISO/TS16332; Diesel Engines - Fuel Filters - Method for evaluating fuel/water separation efficiency. 2006. 